\title{
Analysis of Mitochondrial DNA on Earwax as an Alternative Material for Present and Future Forensic Examination
}

\author{
Lilian Felipe ${ }^{1 *}$ and Rocio Cavazos Guajardo ${ }^{2}$ \\ ${ }^{1}$ Assistant Professor, Lamar University, USA \\ ${ }^{2}$ Doctoral Student, Lamar University, USA
}

Submission: October 03, 2018; Published: October 09, 2018

*Corresponding author: Lilian Felipe, Assistant Professor, Lamar University, USA, Email: lfelipe@lamar.edu

\section{Abstract}

Introduction: Nowadays molecular forensics is a field of science evolving since the1980s, known as DNA fingerprinting. Specimens widely used in DNA examine for identification are blood spots/bloods, semen spots, vaginal swabs, buccal swabs and bones. In addition to these samples, the last objects often used by the perpetrators/victims can be hearing assistive devices or/and hearing aids(headsets/earphones). In its use, earphones are attached to the outer ear skin; therefore, the earwax is suspected to stick to the device. Cerumen have been investigated for the last decades finding an important way to detect specific variations in the mitochondrial DNA (mtDNA) of this type of corporal fluid. The present study discusses relevant information about the literature and how this method is the future for new findings in forensic sciences.

Discussion: Literature showed that Mitochondrial DNA has better durability and relatively higher number of copies than those of nuclear DNA. This leads to greater possibility of success in amplification, given the higher number of mitochondrial DNA copies and the fact that mitochondrial DNA is a single locus that allows recombination. It is controversial the use of earwax as a possible DNA identification tool because of the environmental factors of exposure duration. Controversially, literature shows that this type of fluid has a great opportunity in terms of cell replication and DNA identification.

Conclusions: The mt DNA contained in earwax samples potentials to be a new identification sample for the forensic science. Present studies provide promising evidence for the use of this fluid in different types of identification procedures.

Keywords: Earphone swabs; identification; Mitochondrial DNA (mtDNA); forensics; earwax

\section{Introduction}

DNA is the smallest unit of genetics and are all living creatures ranging from microorganisms to higher organisms such as humans, animals, bacteria, and plants. According Notosoehardjo [1], each human structure has a different DNA content depending on the structure and composition of the cell. A structure with many nucleated cells and little connective tissue generally have high levels of DNA. During the selection taken of the organ to be isolated DNA in a forensic case analysis is important to take in count the circumstances of decomposition of the sample. Every part of the human body can be as a specimen because every cell in the body has the identical DNA sequence, where a child is basically receiving the same amount of genetic material from the mother and biological father.

Procedures of identification in forensic science include fingerprint (dactyloscopy), property, medical, teeth, serology, and exclusion method. Fingerprints and dental sampling are the most specific methods for personal identification. The expansion of future identification methods leads to molecular forensics.
Molecular forensics is an emerging field of science since the early 1980s more methods known as: DNA (Deoxyribonucleic acid) fingerprinting. DNA fingerprinting is a laboratory technique used to establish a link between biological evidence and suspects in a criminal investigation. The DNA sample taken from a crime scene is compared with a DNA sample from a suspect. If the two DNA profiles match, then the evidence belongs to that suspect. Unlikely, if the two DNA profiles do not match, then the evidence cannot have come from the suspect. DNA fingerprinting is also used to found paternity. This method was first

introduced by Jeffreys in 1985, is part of the science of forensic medicine which utilizes knowledge of medicine and biology at the molecular level or DNA.

The most widely used specimens in DNA testing to identify, are specimens of blood spots/blood, semen patches, vaginal swab, buccal swab and bone according to Kusuma (2004). At the crime scene trace evidence would be obtained biologically, trace evidence among objects that the perpetrator or the victim 


\section{Global Journal of Otolaryngology}

frequently used the last time. Nowadays, hearing devices are more prevalent, such as mobile phone which is a headset or earphone. Headset/earphone audio is an electronic device, which is used in mobile phones or MP3s. When earphones are in use, they are attached to the skin, so the outer ear cerumen or earwax sticks to the tool. Drummer [2] described how to do forensic identification through the earwax material attached to the earphones used by offenders. Only until now there has been limited research that specifically describes the effectiveness of using swab earphones for use as identification. Other studies that Sosiawan et al. (2004) investigated the use swab effectivities cerumen in paternity tests. Cerumen, also known as earwax, is mostly classified in two main types: dry or wet earwax. The type of earwax of every individual is dependent on a variant called ABCC11 gene. This gene contains the information for the type of protein process in regards fatty substances. Any changes in the ABCC11 gene may result in less fat being moved into earwax, causing a dry consistency. By the other hand, most people of East Asian descent

have the ABCC11 variant causing dry earwax. Conversely, people from other ethnicities often lack this variant and have wet earwax Petrakis et al. [3]. This special variation allows the differentiation and gene distinction in one of many markers between individual to individual.

DNA identification involves somatic chromosomes, the comparison used is composed of components from a father and a mother. While the examination of mitochondrial DNA, just involves the information of the maternal line. The wide variety of comparators can be used according to the type of cases, for example, can be used comparative grandparents, cousins and others, but the course of analysis used a slightly different (Syukriani, 2012). In mitochondrial DNA (mtDNA) humans have a genetic trait that differentiates it from the nuclear genome. Mitochondrial DNA is passed down only through maternal lines without recombination (through the mother). In the Mitochondrial DNA the daughter cells are entirely donated by the mother and the sperm did not contribute Campbell [4]. The distinctiveness of this inheritance system has been utilized in various fields, namely the determination of affinity, the study of evolution and global migration of modern humans, forensic and identification of genetic disease Wallace [5]. Until recently in United States personal identification through a swab on the earphone/headset with methods of DNA analysis (DNA Profiling) through mitochondrial DNA has not been done. This article may offer answers on matters related to the effectiveness of the use of swab earphone as material identification forensic cases.

\section{Discussion}

In regards earwax sampling, diverse methods were applied depending on the quantity required for analysis including for instance ear swabs commonly applied in forensic testing, mitochondrial DNA paternity testing, etc. The ear swabs could be performed at home by oneself inserting a sterile swab into the inner section of the ear and mildly rotating to collect the sample two to three times if possible, whereas a full swab tip may be enough Seo et al. [6]. By the other side, some techniques for sample collection were applied using tools such as sterilized metal scoops, plastic curettes, wooden spatulas, and the Jobson-Horne probe (Overfield, 1985) [7]. Some studies agree that earwax is like nails, hair and teeth may specify chronic contact with (Hee \& Boyle, 1988). Cerumen has been used for detection of long-term exposure to bio-accumulator xenobiotics like lindane, chlordane, dichlorodiphenyltrichloroethane (DDT), dichlorodiphenyldichlororthylene (DDE), dieldrin, hexachlorobenzene (HCB), and hexachlorocyclohexane (HCH) which cause cancer mortality, using gemcitabine and cisplatin, as well as for detection of environmental exposure to metals Xang et al. [8]. Despite that, the cerumen sampling is much simpler and acceptable than the surgical sampling of other adipose tissues, the results can only reflect cumulative exposure over a period of months or years rather than recent exposure and information relating to the chronic health effects of concern is lacking. By the other hand, earwax was most lately used as an intermediate for monitoring drugs specifically to indicate administration of drugs abuse or drug eased crimes (poisoning). The identification of these drugs includes: antiepileptics, anxiolytics, antipsychotics, etc. Cerumen could be even considered a more promising replacement to conventionally used biological fluids because of its non-invasiveness, comfort of sample collection, smallest sample pre-treatment, and quite less external contamination. In addition to this, is easy to detect the analytes recently administered as well as drugs administered months ago Shokry et al. [9]. Additionally, some other studies describe techniques using postmortem cerumen samples for detection of drugs abuse, which may be associated with the cause of death as opiates, amphetamine, cocaine, methadone and/or other types of byproducts. According to Shokry et al. [9] study, they collected earwax material using cotton swabs dried at room temperature for 24 hours before examination. Results for this study showed different times slot results for each category. In other words, the more exposition to ambient factors resulted in a less quantity of available DNA residual material.

According to Sullivan (1992), mitochondrial DNA endurance is better than nuclear DNA because it has a relatively large number of cells to study, so that has a greater chance of success in the amplification process, given the number of copies of mitochondrial DNA. This agrees to the opinion of Parson and Coble (2001), where they stated that the copy number of mtDNA has more about 500 2000 copies per cell, compared to nuclear DNA which is only two copies per cell and mitochondrial DNA is a single locus that the recombination. By the other hand, mitochondrial DNA have the nature of the power of discrimination in comparison to nuclear DNA. Consequently, mitochondrial DNA is an alternative when faced with the nuclear DNA is degraded condition of the complex or severe. However, if the use of a standard primer on the STR is not able to be detected, then the alternative to perform is primary re-design to reduce amplicon size before using mtDNA.

Additionally, Yudianto et al. [10] performed a sample with earphones that were used for a period of 3 days. After this period 
of usage, the earphones were left at room temperature for a period of 5 days, 10 days, and a maximum of 20 days. During the first two tests, the results indicated a great outcome for the DNA material. By the other hand, the results for the sample left at 20 days indicated that environment affected the levels of DNA. As is known environmental factors such as humidity and temperature of the environment affects the condition of DNA that are used as ingredients in the field of forensic DNA identification, as well as on another DNA testing in the field. By the other hand, the same study discussed the possibility of different methods of preservation and investigation for these types of sampling devices [11].

\section{Conclusion}

It is a potential role of earwax as medium for biological monitoring and a new frontier for medical diagnosis and forensic applications highlighting its advantages in comparison to traditional diagnostic tests. Further research is necessary on the study of earwax as a promising alternative biological fluid. Some limitations were found in this article review, where relatively less data was available on applications of cerumen in medical diagnosis and some of the references could be somehow outdated. That is probably because earwax until recently have been looked upon as a neglected body secretion and thus many years were needed to reach a considerable amount of data supporting the potential diagnostic of earwax. It can be concluded that there are external factors that may affect the environment and the long exposure quantity and quality of DNA from the swab earphone, but still can be an alternative material in forensic identification. In summary, this technique may bring a new non-invasive method to track mtDNA from another kind of fluid.

\section{References}

1. Notosoehardjo I (2001) DNA Forensics; Paternity test, Past, Present, and Future. J For Scien VIII, pp. 34-45.

2. Drummer OH (2010) Forensic toxicology. EXS 100: 579-603.

3. Petrakis NL, King EB, Lee M, Mike R (1990) Cerumen phenotype and proliferative epithelium in breast fluids of United States-born vs. immigrant Asian women: a possible genetic environmental interaction. Breast Cancer Research and Treatment 16: 279-285.

4. Campbell DJ, Jiri Frohlich, George E Price (1973) Problems in laboratory diagnostics of alkaptonuria. Clin Chem 19: 770-773.

5. Wallace DC (1997) Mitochondrial DNA variation in human evolution, degenerative disease and aging. American Journal of Human Genetic 57: 201-223.

6. Seo Y, Uchiyama T, Matsuda H, Shimizu K, Takami Y, et al. (2002) Mitochondrial DNA and STR typing of matter adhering to an earphone. J Forensic Sci 47(3): 605-608.

7. Overfield T (1985) Biologic Variation in Health and Illness: Race, Age, and Sex Differences. ( $1^{\text {st }}$ edn). Addison Wesley Publishing, Boston, USA.

8. Wang XQ Gao PY, Lin YZ, Chen CM (1988) Studies on hexachlorocyclohexane and DDT contents in human cerumen and their relationships to cancer mortality. Biomed Environ Sci 1(2): 138-151.

9. Shokry E, Marques JG, Ragazzo P, Pereira NZ, Filho NRA (2017) Earwax as an alternative specimen for forensic analysis. Forensic Toxicol 35: 348-358.

10. Yudianto A, Sispitasriwan Y, Margaret N (2016) Analysis of earphone swab mitochondrial DNA as an alternative material for identification examination. Folia Medica Indonesiana 52(3): 169-173.

11. Hee SS, Boyle JR (1988) Simultaneous multi elemental analysis of some environmental and biological samples by inductively coupled plasma atomic spectrometry. Anal Chem 60: 1033-1042.

\section{Your next submission with Juniper Publishers will reach you the below assets}

- Quality Editorial service

- Swift Peer Review

- Reprints availability

- E-prints Service

- Manuscript Podcast for convenient understanding

- Global attainment for your research

- Manuscript accessibility in different formats

( Pdf, E-pub, Full Text, Audio)

- Unceasing customer service

Track the below URL for one-step submission https://juniperpublishers.com/online-submission.php 